Clinical Medicine \& Research

Volume 1, Number 3: 201-216

\title{
Review
}

\section{Tobacco Cessation in Primary Care: Maximizing Intervention Strategies}

John D. Anczak, MHS, PA-C, Orthopaedics, Marshfield Clinic-Eau Claire Center, Eau Claire, Wisconsin

Robert A. Nogler, II, MD, Family Practice, Marshfield Clinic-Ladysmith Center, Ladysmith, Wisconsin

[See related article 175 - 176]

\begin{abstract}
The most effective preventive intervention that a clinician can provide for tobacco-using patients against heart disease, cancer, cerebrovascular disease and chronic obstructive pulmonary disease is an empathic, personalized smoking cessation intervention program with extended assistance and follow-up. The goal of the intervention must be complete smoking cessation. Reduction provides no direct health benefits to the individual smoker. Interventions are readily available, but underutilized, in part due to lack of clinician training and organizational support.
\end{abstract}

The present article summarizes the current guidelines for smoking cessation interventions as a framework from which to start. The guidelines incorporate the Transtheoretical Model of patient behavioral change and the "Five A's": Ask, Advise, Assess, Assist and Arrange. Pharmacotherapeutic tools, including nicotine replacement therapies (nicotine gums, patches, nasal sprays, inhalers and new therapies) and non-nicotine therapies (bupropion, clonidine, nortriptyline and other antidepressants and anxiolytics) are considered. Adherence validation methods, new approaches to tobacco and addiction treatment that appear in the recent research literature are reviewed.

Beyond this framework, specific categories of tobacco users (including smokeless tobacco users), cultural and ethnic minorities, adolescents using snuff and bidis, women, Medicaid recipients, and users of multiple forms of tobacco require special consideration.

With this framework and the modifications that may be required for specific categories of patients, practicing clinicians can incorporate into daily practice a successful tobacco cessation intervention program with quit rates approaching $20 \%$.

REPRINT REQUESTS:

John D. Anczak, PA-C

Marshfield Clinic-Eau Claire Center

2116 Craig Road

Eau Claire, WI 54701

Telephone: 715-858-4650

Fax: 715-858-4501

Email: anczak.john@marshfieldclinic.org
KEYWORDS:

Smoking cessation; Tobacco; Cigarettes; Smokeless tobacco; Bidis; Bupropion; Nicotine replacement therapy 


\section{INTRODUCTION}

Caffeine, nicotine and ethyl alcohol are the three most widely consumed psychoactive agents in the world. ${ }^{1}$ Tobacco, particularly cigarette smoking, has long been recognized as a health threat. Since 1964 successive Surgeon Generals have warned the general public about the dangers of smoking. ${ }^{2}$

Nonetheless, tobacco use remains the leading cause of preventable death in the United States, accounting for 430,000 deaths annually. ${ }^{3,4}$ Smoking mortality is a composite of the four leading causes of death: heart disease, cancer, cerebrovascular disease and chronic obstructive pulmonary disease. ${ }^{3}$ Tobacco use is estimated to cause $35 \%$ of all cancers, $33 \%$ of all heart attacks and strokes, and $90 \%$ of chronic obstructive pulmonary disease, including emphysema. 3,5 Smokers who do not quit by age 35 have a $50 \%$ chance of dying from a tobacco-related disease. Their life expectancy is 8 years less than those who have never smoked. ${ }^{6}$ Annually, tobacco usage is estimated to cost $\$ 53$ to $\$ 73$ billion in medical costs, plus an additional $\$ 47$ billion in lost productivity. ${ }^{4}$ The burden on the public through Medicaid and Medicare expenditures varies considerably from state to state, the totals range from $\$ 13$ to $\$ 14$ billion. ${ }^{7,8}$

In $1965,42.4 \%$ of all adults (50.1 million) reported that they were currently smokers, and another $13.6 \%$ (16.0 million) reported that they were former smokers. ${ }^{9}$ By $1997,24.7 \%$ of adults (48.0 million) were current smokers and 23\% were former smokers. Among current smokers in 1997, 41\% had stopped smoking for at least 1 day in the preceding year and $70 \%$ of all smokers wanted to quit. ${ }^{10}$ However, during the 1990s evidence suggested that the rate of decline in smoking had waned. ${ }^{11}$ There is some indication that an increasing number of users (60\% of all smokers in California) smoke less than 15 cigarettes per day, a $9 \%$ increase in the number of "light" smokers between 1996 and 1999.12,13 The national prevention agenda set by the United States Department of Health and Human Services, is to achieve a $12 \%$ adult smoking prevalence rate and a $75 \%$ quit rate by the year 2010.14

Smoking intervention programs have been shown to be costeffective with approximately $\$ 3$ saved for every $\$ 1$ spent in preventive measures. ${ }^{15}$ The addictive nature of nicotine makes tobacco cessation difficult. Long-term tobacco use is maintained by addiction to nicotine. ${ }^{16,17}$ Prolonged use of tobacco products (cigarettes, cigars, pipes, or smokeless tobacco) has now been shown to be associated with increased incidence of stomach cancer. ${ }^{18}$ Nornicotine (a nicotine metabolite) causes aberrant protein glycation (advanced glycation end-products) that are implicated in diabetes, cancer and Alzheimer's disease. ${ }^{19}$ Nornicotine may also catalyze the covalent modification of commonly prescribed steroids, such as cortisone and prednisone. ${ }^{19}$
While it has been shown that a reduction in exposure of nonsmokers to environmental tobacco smoke may have significant health benefits, ${ }^{20-24}$ reducing the number of cigarettes smoked does not provide any health benefit directly to the smoker. ${ }^{25}$ In a study of 19,732 patients, smoking reduction yielded no decrease in mortality from tobacco-related disease. ${ }^{26}$ The only known way to reduce cancer risk in smokers is complete cessation, which results in a $35 \%$ lower risk of death due to tobacco-related illness and a $64 \%$ reduced risk of tobacco-related cancer. ${ }^{27-29}$ The only benefit to the smoker in reducing the number of cigarettes smoked may be greater ease in quitting. In the cohort of 13,415 smokers enrolled in the CoMMunity Intervention Trial (COMMIT) of the National Cancer Institute, $40 \%$ of those who smoked fewer than 15 cigarettes per day had stopped smoking after 5 years, as compared to, $21 \%$ who smoked 15 cigarettes or more. ${ }^{30}$

Effective tobacco interventions are available but underutilized because nicotine is widely used and culturally accepted. Clinicians do not inquire about tobacco usage, do not use available interventions, are under time constraints and may not believe the effort of tobacco cessation intervention is worth the benefit to the patient. ${ }^{1}$ United States medical schools inadequately teach tobacco intervention skills. There is a lack of integration of tobacco dependence information throughout all four years of medical school curricula. There is also a lack of specific training in smokeless tobacco intervention, tobacco intervention training that addresses cultural issues, and long-term studies showing training is retained. ${ }^{31}$ Physician use of clinical practice guidelines is low in the United States. The Public Health Service has issued updated smoking cessation guidelines for patients and physicians, healthcare administrators, insurers and purchasers. Successful guideline implementation is highly dependent on administrative supports from healthcare organizations and insurers. ${ }^{32}$

This article summarizes the current smoking cessation guidelines that can serve as an effective framework for tobacco cessation intervention. Special considerations when treating smokeless tobacco users, cultural and ethnic minorities, adolescents, women, Medicaid recipients and users of multiple forms of tobacco are also presented.

\section{CLINICAL INTERVENTION FRAMEWORK FOR SMOKING CESSATION}

Smoking cessation is the most important, cost-effective preventive maintenance that clinicians can offer patients who smoke. It has been called the "gold standard" of prevention interventions by David Eddy, a leading authority on guidelines and cost-effectiveness analysis. ${ }^{33}$ Primary care clinicians play a key role in identification, assessment and treatment of smokers. It is essential to provide cessation intervention for all smokers at each visit. ${ }^{34-37}$ At least $70 \%$ of smokers see a physician annually, which means that physicians are missing a prime opportunity to improve the health of their patients. ${ }^{35}$ 
Brief advice and encouragement during one routine office visit results in a 5\% estimated quit rate without relapse at 1 year. ${ }^{38}$ Higher quit rates are achievable with more fully developed programs. With an empathic, personalized smoking cessation intervention program, smokers that abstain for 5 years are very likely to remain abstinent after 11 years. ${ }^{39}$

Effective smoking prevention interventions based on the National Cancer Institute's "Five A's" model, the Agency for Healthcare Research and Quality guidelines, and the Transtheoretical Model (TTM) of behavioral change, have been demonstrated to be effective in identifying and treating tobacco users. ${ }^{34-37}$

\section{Clinical practice guideline}

A partnership between the Federal Government and nonprofit organizations (Agency for Healthcare Research and Quality; Centers for Disease Control and Prevention; National Cancer Institute; National Heart, Lung, and Blood Institute; National Institute on Drug Abuse; Robert Wood Johnson Foundation; and University of Wisconsin Medical School's Center for Tobacco Research and Intervention) developed the current Clinical Practice Guideline, "Treating Tobacco Use and Dependence." This guideline incorporates the "Five A's" model:36

- Ask about smoking.

- Advise smokers to stop.

- Assess the smoker's willingness to stop.

- Assist those smokers willing to stop.

- Arrange follow-up.

Table 1. Smoking assessment form.

Name:

1. Do you now smoke cigarettes?

2. Does the person closest to you smoke cigarettes?

3. How many cigarettes do you smoke a day?

4. How soon after you wake up do you smoke your first cigarette?

5. How interested are you in stopping smoking?
Not at all
A little
Some
A lot
Very

6. If you decided to quit smoking completely during the next 2 weeks, how confident are you that you would succeed?

Not at all

A little

Some

A lot

Very

Physician Use:

\begin{tabular}{|c|c|c|c|c|c|c|c|}
\hline \multirow{2}{*}{ Visit date } & \multicolumn{3}{|c|}{ Quit date established? } & \multirow{2}{*}{$\begin{array}{l}\text { Date of } \\
\text { F/U visit }\end{array}$} & \multirow{2}{*}{$\begin{array}{c}\mathrm{CO} \\
\text { (ppm) }\end{array}$} & \multirow{2}{*}{$\begin{array}{l}\text { Therapy } \\
\text { prescribed }\end{array}$} & \multirow{2}{*}{ Comments } \\
\hline & Yes & No & When & & & & \\
\hline & & & & & & & \\
\hline & & & & & & & \\
\hline & & & & & & & \\
\hline & & & & & & & \\
\hline & & & & & & & \\
\hline & & & & & & & \\
\hline & & & & & & & \\
\hline
\end{tabular}


Table 2. Fagerström test for nicotine dependence.

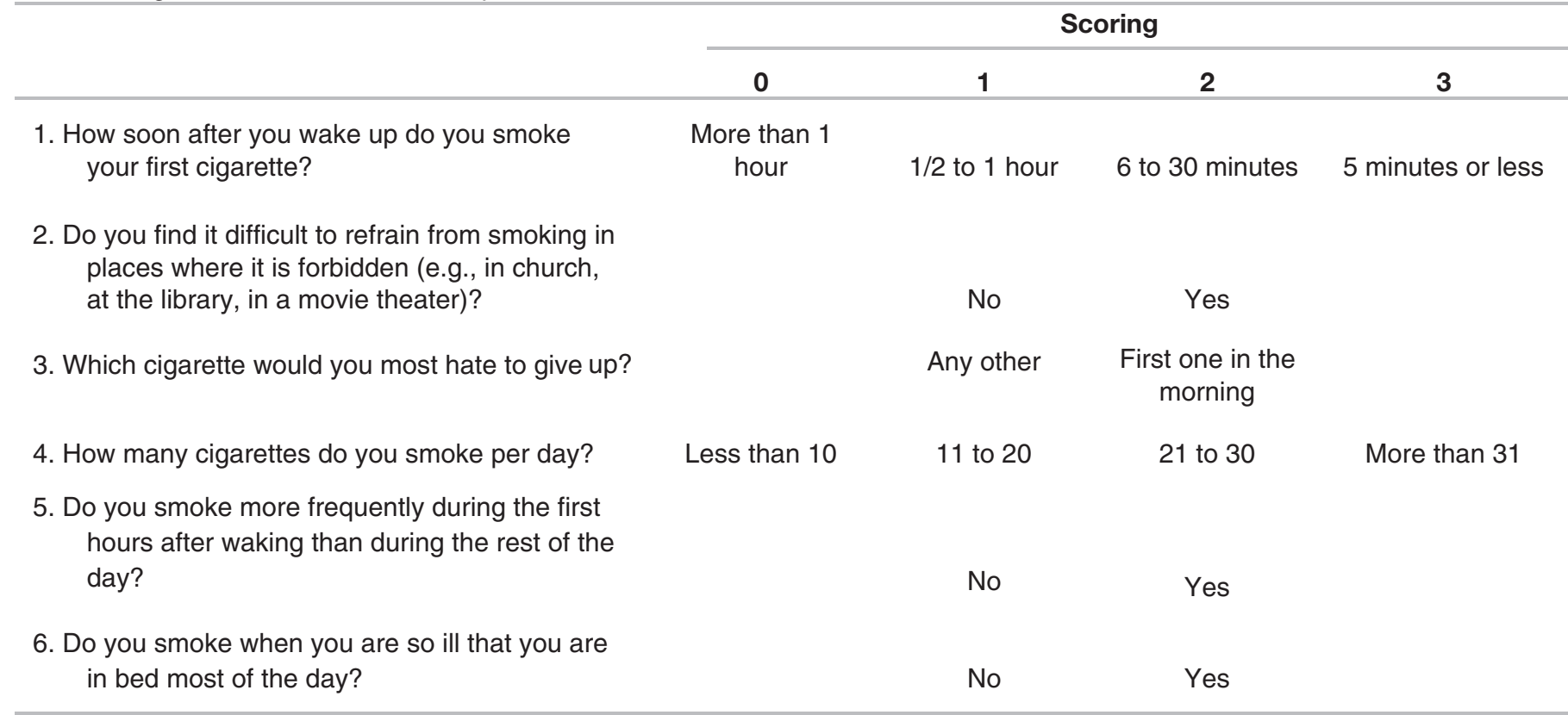

Scoring: 0-4 low; 5 medium; 6-7 high; 8-10 very high level of nicotine dependence. A total of 7 or greater may indicate more severe withdrawal symptoms, greater difficulty quitting, and possibly the need for higher dose nicotine supplements.

Adapted from Heatherton TF, Kozlowski LT, Frecker RC, Fagerström KO. The Fagerström test for nicotine dependence: a revision of the Fagerström tolerance questionnaire. $\mathrm{Br} \mathrm{J}$ Addict 1991;86:1119-1127.

Systematically identify all tobacco users by Asking at every visit. Give clear, strong and personalized Advice about the importance of total cessation. Patients not willing to quit despite clinical advice may be uninformed, concerned about the effects of quitting, or discouraged by previous relapses. Once identified, a smoking Assessment form should be used for all patients and the information updated by placing a smoker identifier sticker on the chart (table 1). The Fagerström test (Therapeutic Guidelines Limited, North Melbourne, Australia) for nicotine dependence (table 2) has proven useful in determining the patient's level of nicotine dependence, likely severity of withdrawal symptoms, difficulty in quitting and possible need for higher doses of nicotine supplements.

Pledge to Assist patients when they are ready to quit. 40 Ask questions at each visit that help the patient identify reasons to quit and barriers to quitting. Motivational interventions for patients unwilling to quit at the present time are characterized by the "Five R's":

- Relevance

- Risks

- Rewards

- Roadblocks

- Repetition ${ }^{24-36,41}$ (table 3)

Assist patients willing to quit by setting a quit date and preparing the patient for the quit date. A complete stop quit date is extremely important to success. Smoking $0-1$ cigarettes per day/week during the first 2 weeks has very high predictive value for failure. ${ }^{42}$ In addition, provide selfhelp materials, quitting advice and nicotine replacement therapy (NRT). A smoking contract can be useful to estab- lish a quit date and having the patient simply state: 41 "I understand that stopping smoking is the single best thing I can do for my health and that my health professional has strongly encouraged me to quit."

Make patients aware of nicotine withdrawal symptoms so they know what to expect (table 4). If the clinician and patient feel a more intensive treatment is warranted, the patient can be referred to an intensive treatment program. Arrange follow-up contact for all patients attempting to quit. ${ }^{34,35}$ Figure 1 diagrams a flow chart of the current smoking cessation guidelines. Relapse into smoking can occur at any stage, at which point efforts should be renewed at the level appropriate to the patient.

Table 4. Nicotine withdrawal symptoms.

Frequency of occurrence

\begin{tabular}{ll}
\hline Anxiety & $88 \%$ \\
Irritability & $80 \%$ \\
Difficulty concentrating & $73 \%$ \\
Restlessness & $71 \%$ \\
Tobacco craving & $62 \%$ \\
Gastrointestinal problems & $33 \%$ \\
Headaches & $24 \%$ \\
Drowsiness & $22 \%$ \\
\hline From reference 16. &
\end{tabular}


Table 3. Enhancing motivation to quit tobacco use-the "Five R's" for the patient unwilling to quit at this time.

Relevance Encourage the patient to indicate why quitting is personally relevant, being as specific as possible. Motivational information has the greatest impact if it is relevant to a patient's disease status or risk, family or social situation (e.g., having children in the home), health concerns (morning cough, better sense of taste and smell, better breath) age, sex, and other important patient characteristics (e.g., prior quitting experience, personal barriers to cessation).

Risks The clinician should ask the patient to identify potential negative consequences of tobacco use. The clinician may suggest and highlight those that seem most relevant to the patient. The clinician should emphasize that smoking low-tar/low-nicotine cigarettes or the use of other forms of tobacco (e.g., smokeless tobacco, cigars, and pipes) will not eliminate these risks. Examples of risks are:

Acute risks: shortness of breath, exacerbation of asthma, harm to pregnancy, impotence, infertility, increased serum carbon monoxide levels.

Long-term risks: myocardial infarction and strokes, lung and other cancers (larynx, oral cavity, pharynx, esophagus, pancreas, bladder, cervix), chronic obstructive pulmonary diseases (chronic bronchitis and emphysema), long-term disability and need for extended care.

Environmental risks: increased risk of lung cancer and heart disease in spouses; higher rates of smoking by children of tobacco users; increased risk for low birth weight, sudden infant death syndrome, asthma, middle ear disease, and respiratory infections in children of smokers.

Rewards The clinician should ask the patient to identify potential benefits of improved health: food will taste better; improved sense of smell; save money; feel better about yourself; home, car, clothing, and breath will smell better; can stop worrying about quitting; set a good example for children; have healthier babies and children; not worry about exposing others to smoke; feel better physically; perform better in physical activities; reduced wrinkling/aging of skin.

Roadblocks The clinician should ask the patient to identify barriers or impediments to quitting and note elements of treatment (problem solving, pharmacotherapy) that could address barriers. Typical barriers might include: withdrawal symptoms, fear of failure, weight gain, lack of support, depression, enjoyment of tobacco.

Repetition The motivational intervention should be repeated every time an unmotivated patient visits the clinical setting. Tobacco users who have failed in previous quit attempts should be told that most people make repeated quit attempts before they are successful.

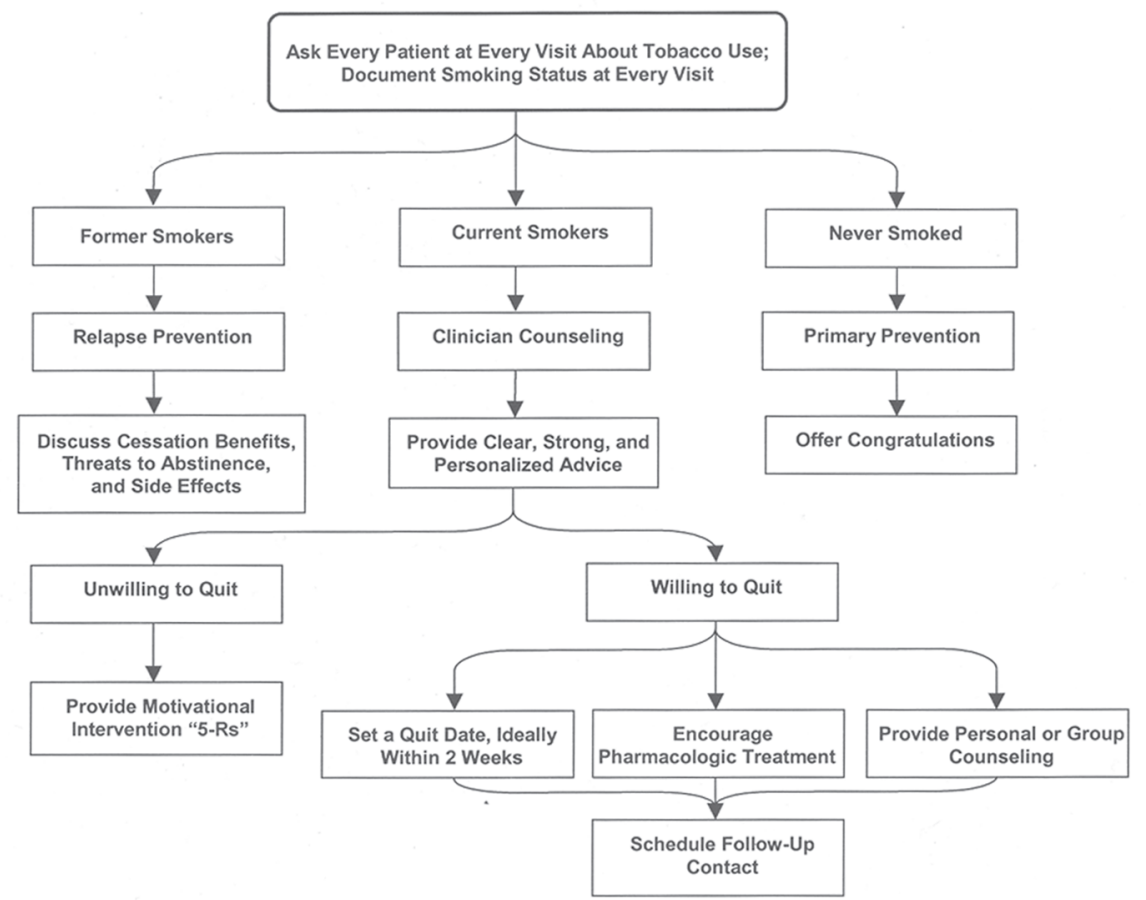

Figure 1. Smoking cessation flow chart. 
Transtheoretical Model

Smoking cessation requires a behavior change. ${ }^{34}$ The TTM further helps understand a smoker's readiness to adopt smoking cessation interventions. This model, developed by Prochaska and DiClemente, has been applied to several health behaviors as well as smoking cessation. ${ }^{43}$ Smokers will transition through 5 stages of behavioral change before, during and after the smoking cessation process: precontemplation, contemplation, preparation, action and maintenance.

\section{PRECONTEMPLATION STAGE}

The smoker is not seriously considering quitting in the next 6 months. Motivational interventions to increase awareness of adverse effects of smoking are beneficial. Smokers in this stage overestimate the benefits of smoking, underestimate the risks and avoid information to help them change. ${ }^{44}$ In this stage, the clinician's role is primarily to advise and inform the patient.

\section{CONTEMPLATION STAGE}

The smoker is seriously planning to quit smoking in the next 6 months, however not immediately and no quit date is set. At this stage, smokers recognize that the risks of smoking outweigh the benefits. Smokers are the most ambivalent to change and are often stuck in "chronic contemplation." They tend to substitute thinking for acting. Motivational interventions to increase awareness of the adverse effects of smoking are beneficial. Clinicians should emphasize the negative effects of smoking. 44,45

\section{PREPARATION STAGE}

The smoker is planning to quit and a stop date has been set in the next month. Clinical assessment using the Fagerström test is useful at this point. Assistance in initiating steps toward cessation are pursued, e.g., delaying the first cigarette of the morning, cutting down, prior quit attempts with a duration of 24 hours, informing family and friends, and initial trials of NRT therapies. The smoker identifies that the risks outweigh the benefits. Interventions to assist patients in this stage to quit smoking include focus on NRT and developing behavior modification skills. ${ }^{44}$

\section{ACTION STAGE}

Individuals have taken steps to stop smoking. Smokers may quit by using medication and NRT, behavior modification, willpower, an informal quitting strategy, or a combination of some or all of these methods. ${ }^{46}$ This stage lasts from onset of the efforts, until 6 months after cessation. This is also the most frequent stage for relapse, which varies with therapy, coffee and alcohol consumption, history of depression and gender. ${ }^{44,47-49}$ High initial relapse occurs during the first 2 to 3 weeks (almost 50\%). This then tapers off during the next 2 to 3 months. Thus, initial support is most important. Support after 3 to 4 months has much smaller effects on relapse. Therefore, interventions addressing relapse, prevention and rewarding positive behavior are most effective. Frequent contact with the clinician is important for continuation of this stage, redirecting efforts and celebrating successes.

\section{MAINTENANCE STAGE}

At this stage, the patients have not smoked for 6 months. Successful patients are now avoiding relapse. Relapse occurs often. Most successful quitters relapse and cycle through the stages an average of 3 to 4 times before becoming free from cigarettes. ${ }^{50}$

The TTM describes the process of behavior change through a continuum of stages. The TTM permits tailoring of interventions to match the smoker's needs. Additionally, movement through the stages is another measure of intention to change smoking behavior. ${ }^{51}$ Therefore, the clinician's role is:

- Motivate smoking patients to stop.

- Assist motivated patients to succeed in quitting.

Monitoring motivational levels is the key to behavior change with smoking cessation. Highly motivated patients are more successful with smoking cessation than less motivated patients. ${ }^{52}$

Other new behavioral change theories are evolving that promise to aid in the understanding of patient motivations to quit tobacco use as well. King et al. ${ }^{53}$ have described a novel conceptualization of health behavior change, describing factors that control the decision to initiate new patterns of behavior and maintain them. Williams et al. ${ }^{54}$ have described a self-determination theory, the only empirically derived theory that emphasizes patient autonomy.

\section{PHARMACOTHERAPY}

Nicotine is fast-acting, arriving in the brain within 7 seconds of inhalation. It stimulates the adrenal glands resulting in discharge of epinephrine, resulting in the "kick" or "fix" experienced by the smoker. The rush of adrenaline causes a sudden release of glucose, an increase in blood pressure, and increased respiratory and heart rates. Nicotine also suppresses insulin output creating a chronic slight hyperglycemia. In the brain nicotine causes dopamine release and decreases the inhibitory (gamma amino butyric acid) response in regions controlling pleasure and motivation. Even a brief exposure to nicotine results in the long-term excitation of the brain's reward areas. ${ }^{55-57}$

Pharmacotherapy can be divided into two groups: nicotine replacement therapy (NRT) and non-NRT. NRT increases abstinence rates by 2 to 3 times that of placebo. ${ }^{35}$ All pharmacotherapy treatments approximately double the cessation rates. Therefore, patient preference and prior experience is the basis for treatment choice. Table 5 lists the advantages and disadvantages of each pharmacologic treatment choice.

NRT is not advised for patients in immediate post myocardial infarction (within 4 weeks), patients with serious arrhythmias, worsening angina pectoris, or pregnant and lactating women. ${ }^{51}$ NRT works by supplanting nicotine from cigarettes and relieving or preventing nicotine withdrawal symptoms. Non-NRT alters or alleviates withdrawal symptoms as well. 
Absorption from NRT-like gum and patches is gradual and time is allowed for development of tolerance to nicotine withdrawal in the brain. The stimulant and euphoric effects of rapidly absorbed nicotine from cigarette smoking does not occur. However, the high levels of nicotine maintained in the brain by NRTs prevent the nicotine withdrawal symptoms and thus the efficacy of NRT. ${ }^{58}$

Clinicians may recommend any of 5 pharmacotherapies: nicotine gum, nicotine patch, nicotine nasal spray, nicotine inhaler and non-NRTs. ${ }^{59}$ As with all pharmacologic therapies, concomitant personal and telephone counseling significantly increase cessation rates. ${ }^{35,60}$

\section{Nicotine gum}

Nicotine gum (Nicotine Polacrilex, Nicorette [Glaxo Smith Kline Consumer Healthcare LP, Pittsburgh, PA]) has been available by prescription since 1985 and over the counter since $1996 .{ }^{46}$ The pharmacodynamics of gum cause a gradual rising and falling of nicotine levels throughout the day. Repeated chewing of the nicotine gum delivers nicotine over time. Nicotine levels drop when the gum is not chewed and overnight during sleep. A daily cycle of neuroadaptation and abstinence develops, just like smoking cigarettes, but the amplitude of the cycles is blunted. ${ }^{58}$ Nicotine gum is a proven agent with smoking cessation. There is some evidence that it works best in the short-term in combination with additional agents such as other NRTs or bupropion hydrochloride (Zyban [Glaxo Smith Kline, Research Triangle Park, NC]). ${ }^{61}$ Over the long-term, however, combined therapy has no effect. ${ }^{62}$

Appropriate patient education is required for optimal use of the nicotine gum. Chew the gum until a "peppery" taste or tingling sensation occurs, then "park" the gum between

Table 5. Advantages and disadvantages of pharmacologic treatments for smoking cessation.

\begin{tabular}{|c|c|c|}
\hline Treatment & Advantages & Disadvantages \\
\hline Patch and/or gum & $\begin{array}{l}\text { Available over the } \\
\text { counter }\end{array}$ & $\begin{array}{l}\text { Not approved by } \\
\text { FDA; avoid use } \\
\text { with dentures; } \\
\text { temporomandibular } \\
\text { joint disorder; } \\
\text { adhesive allergies }\end{array}$ \\
\hline $\begin{array}{l}\text { Nicotine nasal } \\
\text { spray }\end{array}$ & $\begin{array}{l}\text { Higher, quicker } \\
\text { nicotine levels }\end{array}$ & $\begin{array}{l}\text { Unpleasant adverse } \\
\text { events initially; } \\
\text { avoid use with } \\
\text { chronic nasal } \\
\text { allergies }\end{array}$ \\
\hline Nicotine inhaler & $\begin{array}{l}\text { Mimics hand-to- } \\
\text { mouth behavior }\end{array}$ & Low nicotine levels \\
\hline $\begin{array}{l}\text { Bupropion } \\
\text { hydrochloride }\end{array}$ & $\begin{array}{l}\text { Non-nicotine; } \\
\text { can be used in } \\
\text { combination with } \\
\text { patch; decreased } \\
\text { weight gain; mood } \\
\text { stabilization with } \\
\text { nicotine withdrawal }\end{array}$ & $\begin{array}{l}\text { Must screen for } \\
\text { seizures }\end{array}$ \\
\hline
\end{tabular}

From reference 59. cheek and gum, to facilitate nicotine absorption through the oral mucosa. Repeat the process of intermittently "chewing and parking" for about 30 minutes. Daily, patients may chew up to 30 pieces $(2 \mathrm{mg})$ or 20 pieces $(4 \mathrm{mg})$ of the gum. Over-the-counter gum labels recommend chewing 1 to 2 pieces per hour. Start most smokers on $2 \mathrm{mg}$ gum. General guidelines are: use the $2 \mathrm{mg}$ dosage for smokers who smoke fewer than 25 cigarettes per day, and the $4 \mathrm{mg}$ dosage for smokers who smoke at least 25 cigarettes per day. ${ }^{51}$ Clinicians can use the Fagerström nicotine addiction test (table 2) to determine if the patient is highly addicted to nicotine. Instruct patients to chew the gum on a fixed schedule, at least 1 piece every 1 to 2 hours, instead of ad lib use. ${ }^{51}$ Average smokers use 10 to 15 pieces per day initially to achieve abstinence. Also, patients must avoid drinking or eating anything 15 minutes prior to and during chewing gum. Acidic beverages interfere with mucosal absorption of nicotine. The over-the-counter label recommends this treatment for 6 weeks followed by a 6 -week taper. However, some studies suggest longer-term use is more effective. 59

Advantages of the gum include having a behavior to use with an urge to smoke that actively controls nicotine mood changes. Disadvantages include great effort to chew enough gum and adverse side effects that may include sore mouth, throat or jaw, hiccups, dysgeusia, dyspepsia, nausea, flatulence and gastrointestinal discomfort. 46

\section{Nicotine patch}

The pharmacodynamics of the transdermal NRT is different from nicotine gum. Nicotine levels rise gradually and then plateau for most of the day as the patch diffuses nicotine through the skin and into the bloodstream at a constant rate. ${ }^{46,58,63,64}$ Nicotine patches are the preferred method of NRT because of the ease of use and high concentrations of nicotine delivered. The nicotine patch is available in several formulations that vary in strength and duration of action. Patches are worn for 16 or 24 hours per day. The 24-hour patch has the advantage of controlling morning smoking urges by producing higher blood nicotine levels upon awakening. The 24-hour patch may be associated with sleep disturbances, but the 16-hour patch is not. ${ }^{46}$

Starting doses are 21 to $22 \mathrm{mg}$ (24-hour patch) and $15 \mathrm{mg}$ (16-hour patch). ${ }^{46}$ Treat most light smokers with a standard dose patch, 21 to $22 \mathrm{mg} / 24$ hours. Again, the Fagerström scale can also be used to guide initial dosing for heavy smokers with high nicotine dependence scores. High dose nicotine patch therapy is safe, provides complete replacement, improves relief of withdrawal symptoms and increases overall efficacy. ${ }^{61}$

A new patch is applied each morning on a hairless location between the neck and waist. After 4 to 6 weeks the dose is tapered to an intermediate level, $14 \mathrm{mg} / 24$-hour. Following an additional 2 to 4 weeks, apply the lowest dose $7 \mathrm{mg} / 24$ hour to complete the taper. Note that the Nicotrol patch (Pharmacia and Upjohn AB, Sweden) label instructions state to use the patch for 16 hours/day for 6 weeks without 
tapering. The duration of patch use ranges from 6 to 12 weeks, depending on specific patient characteristics (e.g., prior experience with the patch, amount smoked and amount of nicotine dependence). ${ }^{42,51}$

Advantages of the patch, as mentioned, are ease of use, minimal side effects and demonstrated efficacy. Disadvantages include potential adverse health consequences of sustained levels of nicotine in the body. 58

Adverse effects of the nicotine patch include localized skin irritation characterized by erythema, pruritus, or burning under the patch. ${ }^{46} \mathrm{Up}$ to $50 \%$ of patients have localized skin reaction with less than $5 \%$ requiring discontinuation of the nicotine patch therapy. Reactions are self-limiting. Most erythema will disappear spontaneously after 1 to 2 days without treatment. Rashes may be treated with steroid creams and by rotating patch sites regularly. ${ }^{51}$ Other adverse effects include generalized rash, headache, nausea, vertigo and dyspepsia. ${ }^{46}$

\section{Nicotine nasal spray}

Nicotine nasal spray (Nicotrol NS [Pharmacia and Upjohn AB, Sweden]) was approved in March 1996 for prescription use. The nasal spray delivers nicotine more rapidly than gum, patch or inhaler, and mimics the nicotine bolus from cigarettes. ${ }^{60}$ Similar to nicotine gum, the nicotine nasal spray is used in place of smoking when the patient craves nicotine. Plasma nicotine levels peak within 10 minutes and are about two-thirds those of cigarettes. ${ }^{59}$ Smokers use 1 to 2 puffs per hour for 3 months. Initial concerns that smokers may become dependent on the rapid delivery of nicotine nasal sprays have not been shown in clinical trials. 60 Nicotine nasal spray doubled quit rates, like nicotine gum and patch, when compared to placebo. 59

Educate patients on the proper use of the inhaler. One spray of $0.5 \mathrm{mg}$ into each nostril equals one dose of $1 \mathrm{mg}$. Patients may use 1 or 2 doses per hour, not to exceed 5 doses per hour or 40 doses per day. An average smoker uses 15 doses per day, decreasing the dosage over time. The medication is sprayed against lower nasal mucosa. It should not to be sniffed, swallowed, or inhaled. Expect to use one to two canisters per week without careful follow-up. More than two canisters per week should be prescribed only with careful supervision and follow-up. Instruct smokers to use the nasal spray as needed for up to 12 weeks, including the tapering period. ${ }^{61}$

Adverse effects of nicotine nasal spray include headache, burning, rhinitis, watering eyes, nasal or throat irritation, sneezing and coughing. These adverse reactions tend to occur in the first few days and decrease within the first week. ${ }^{46,59}$

\section{Nicotine inhaler}

The nicotine inhaler (Nicotrol Inhaler [Pharmacia and Upjohn AB, Sweden]) has been available in prescription form since 1998. As with other NRTs, it doubles the cessation rates comparable to placebo. The inhaler may be the best choice for smokers that need a substitute for the hand to mouth behavior, and the tactile/sensory stimulation that cigarettes provide. It is also effective as a combination therapy with other NRT agents and bupropion. ${ }^{61}$

The "inhaler" designation is a misnomer. The device does not deliver nicotine to the lungs. Each puff on the inhaler delivers $13 \mathrm{ng}$. To receive levels similar to most cigarettes, over 20 minutes, 80 puffs are needed to get $2 \mathrm{mg}$ of nicotine. Absorption occurs from the oral and pharyngeal mucosa and gastrointestinal tract secondary to swallowing. Therefore, the pharmacokinetics and dependence risks of the inhaler are similar to nicotine gum. The blood nicotine levels are lower with the inhaler than with any other NRT. The recommended initial daily dose is a minimum of 6 capsules and up to 16 capsules. ${ }^{46,59-61}$ Adverse effects include throat irritation and coughing; it is contraindicated with bronchospastic disease. 46,59

\section{Non-NRTs}

Generally, the various forms of NRT increase smoking quit rates relative to placebo, but they generally do not result in rates of over $20 \%$ in one year. ${ }^{65}$ To increase these rates, non-nicotine agents have been employed, particularly drugs that modulate noradrenergic neurotransmission (bupropion, nortriptyline). These agents are generally more effective than those affecting serotonin (selective serotonin reuptake inhibitors, buspirone, ondansetron). ${ }^{65}$ There is no consistent evidence that anxiolytics and selective serotonin reuptake inhibitors aid smoking cessation, but the available evidence does not rule out a possible effect. 66

\section{BUPROPION HYDROCHLORIDE}

Since 1998, bupropion hydrochloride (Zyban) has been available as an aid to smoking cessation by prescription. Bupropion is an aminoketone antidepressant that weakly inhibits both noradrenergic and dopaminergic uptake. ${ }^{61}$ It is believed to work based on the dopaminergic activity affecting the mesolimbic system and nucleus accumbens, which is the pleasure reinforcing area of the brain for addictive drugs. ${ }^{67}$ It also affects the noradrenergic activity in the locus caeruleus, which activates higher cortical functions such as alertness, concentration and memory. Lack of norepinephrine stimulation with nicotine withdrawal may account for withdrawal symptoms. ${ }^{61}$

Clinical trials showed cessation rates similar to NRT. Bupropion may also decrease weight gain associated with smoking cessation. Bupropion is a better choice for females and other smokers who use weight gain as an objection to smoking cessation. ${ }^{61}$ It is also an option for smokers who do not want to try NRT, who have relapsed, or who have failed on NRT.

Bupropion is most effective in combination therapy. One study identified bupropion combined with the nicotine patch as having achieved higher cessation rates than with either as a monotherapy. ${ }^{68}$ Smokers begin taking bupropion 1 week prior to their quit date. Instruct patients to continue smoking 
for the first week and to stop smoking by the end of the second week. The recommended dosage is $150 \mathrm{mg}$ once daily for 3 days and subsequently $150 \mathrm{mg}$ twice daily for 7 to 12 weeks. Ensure the dosing interval is a minimum of 8 hours. Recommend that the second dose be taken in late afternoon or early evening to avoid insomnia. ${ }^{61}$ Again, bupropion can be used as monotherapy or with NRT (e.g., nicotine patch).

Adverse effects of bupropion include insomnia and dry mouth. Bupropion can decrease the seizure threshold. Seizures may occur in $0.1 \%$ of patients. ${ }^{69}$ Screening questions to identify patients at high risks for seizures should be asked:

- Active seizure disorder.

- History of seizures.

- History of central nervous system trauma, including stroke, brain surgery or significant head injury with loss of consciousness.

- Use of drugs that lower seizure threshold (e.g., alcohol, neuroleptics).

- Eating disorders (anorexia nervosa, bulimia).

- Use of high bupropion dose (>300 mg/day). Bupropion is contraindicated in patients using monoamine oxidase inhibitors.

If pharmacotherapy fails, remind the smoker that it may take several attempts to quit. Look for reasons why the last treatment failed, including poor medication adherence and comorbid psychiatric problems (e.g., alcohol abuse, depression, etc.). Remind smokers that it may take several attempts before achieving success. ${ }^{59}$ Note that simple retreatment of NRT failure with the same method is not usually successful. Suggest an alternative NRT (e.g., nicotine nasal spray, nicotine inhaler, or bupropion, etc.). ${ }^{59}$ Studies suggest combined therapy of bupropion and nicotine patches, or nicotine patch and gum, produce higher quit rates for smokers determined to quit. $59,60,68$ Keeping in mind personal preferences, recommend bupropion for patients who smoke in response to negative mood states, or those who report strong moodrelated withdrawal symptoms in prior quit attempts. ${ }^{70}$

\section{CLONIDINE}

Clonidine is a centrally acting $\alpha_{2}$-adrenergic agonist that dampens sympathetic nervous system activity (used primarily in the management of hypertension). A small number of trials have shown that clonidine may be effective in promoting smoking cessation, but prominent side effects limit its usefulness for this purpose. ${ }^{71}$

\section{ANTIDEPRESSANTS AND ANXIOLYTICS}

Nortriptyline is a tricyclic antidepressant that blocks reuptake of norepinephrine and serotonin. It has been studied and shows some promise, ${ }^{72,73}$ but is not yet been approved by the U.S. Food and Drug Administration for smoking cessation treatment.

Because depression and anxiety are associated with cigarette smoking, a variety of other antidepressants and anxiolytics have been tested (buspirone, doxepin and fluoxetine hydrochlorides), but while the results have been promising, investigations are too preliminary yet to draw valid conclusions as to their efficacy. ${ }^{74}$

\section{NEW NRTS AND ALTERNATIVE THERAPIES}

New forms of NRT that are particularly appealing to youth regularly appear in the marketplace and on the Internet. Physicians should remain vigilant for patients who use these products and advise them accordingly. The U.S. Food and Drug Administration has warned sellers of nicotine lollipops and lip balm that their products are illegal, and that bottled nicotine water is an unapproved drug. ${ }^{75,76}$ Several alternative therapies have been promoted to reduce withdrawal symptoms, including hypnotherapy, acupuncture, acupressure, laser therapy and electrostimulation, but none have proven to be useful. 77,78

\section{MAXIMIZING PHARMACOLOGIC EFFECTIVENESS}

To enhance the safety and efficacy of all the pharmacologic agents for nicotine withdrawal, provide written instructions for proper use, individualize dose and duration of therapy, schedule frequent office visits or phone calls to monitor patient response, and adjust dose and duration of treatment accordingly. 61 The patient should be checked every 1 to 2 weeks. Medications should be prescribed in 2-week doses. If abstinence is not achieved within 2 weeks, once again address medications and motivations. Discontinue therapy if smoking is at or near original levels after 4 weeks. If prior unsuccessful attempts were with a single medication change to combination therapy.

\section{METHODS OF VALIDATION}

Providers should also be aware that urine tests are available for monitoring patients if deemed necessary and appropriate. Breath carbon monoxide concentration has been demonstrated to provide an easy, noninvasive and immediate way of assessing a patient's smoking status. ${ }^{79}$ Cotinine, a metabolite of nicotine excreted in the urine, can be used to monitor NRT adherence, but cannot distinguish NRT versus tobacco sources. ${ }^{54}$ Anabasine and anatabine are tobacco alkaloids (not nicotine metabolites) that are excreted in the urine and can be used to validate abstinence or measure the extent of tobacco use in persons undergoing NRT. ${ }^{80}$

\section{FUTURE APPROACHES TO TREATING TOBACCO ADDICTION}

Other approaches for treating tobacco abuse are now being investigated. They include other ways to administer nicotine, a vaccine to prevent nicotine from crossing the blood-brain barrier and agents that alter the metabolism of nicotine. ${ }^{73}$ Again, investigations are too preliminary to draw valid conclusions as to their efficacy.

More promising is the discovery of gamma-vinyl GABA (GVG). This compound is proving useful in the laboratory with some of the most troublesome illicit drugs, but has yet 
to be tested for nicotine addiction. It is the first therapeutic agent that successfully combats the three major components of drug addiction: $81-83$

- Direct neurochemical effects.

- Behavioral effects.

- Neurochemical changes triggered by drug-related environmental cues.

The ways people smoke and respond to carcinogen exposure are highly variable. Switching to light- or low-tar cigarettes actually increases risk in some smokers. ${ }^{27}$ The search is underway for the gene(s) and functional genetic polymorphisms responsible for nicotine metabolism and bupropion kinetics that may make smokers with variants more vulnerable to abstinence symptoms and relapse. ${ }^{84}$ An underlying assumption of genetic testing is that the results will motivate high-risk individuals to reduce harmful exposures, increase their surveillance for disease and increase their seeking for preventive treatments. ${ }^{85}$ Physicians need to consider whether knowledge about genetic susceptibility will alter patient behavior or management, before recommending genetic testing to assess risk for disease. Tests have shown that knowledge of an increased risk of lung cancer does not improve smoking cessation success. ${ }^{85}$

\section{GROUPS REQUIRING A MODIFIED APPROACH}

While the above approach to smoking intervention provides a useful framework from which to begin, altered approaches and special considerations need to be given when treating various categories of tobacco users.

\section{Smokeless tobacco users}

Smokeless tobacco (spit tobacco, dip, chew and snuff) is perceived as safer than smoking tobacco. Cancer, heart attacks and emphysema are not caused by nicotine, but by some of the other 3,000 products of tobacco combustion. For this reason, some recommend the use of smokeless tobacco as a stepping-stone in tobacco cessation, particularly in inveterate smokers. 86,87

However, moist snuff and chewing tobacco present a risk for cancer of the oral cavity, gastrointestinal and upper respiratory sites, with dry snuff usage presenting an even higher risk. ${ }^{88,89}$ Smokeless tobacco contains nitrosamines at levels 100 times that found in bacon, beer and other foods, as well as polyaromatic hydrocarbons and radioactive polonium. ${ }^{90}$ Continual use can lead to gingival recession and snuff-induced oral leukoplakia. That converts to dysplastic lesions and verrucous or squamous carcinomas in $3 \%$ to $5 \%$ of cases. ${ }^{91}$ Senses of taste and smell are reduced so users generally eat more salty and sweet foods.

The amounts of nicotine absorbed, and the distribution and elimination are the same as with smoked tobacco. Nicotine absorbed from smokeless tobacco is still a euphoriant and reinforcer, and causes neuroadaptation that leads to tolerance and physiological dependence. ${ }^{92}$ Hence, there remains good reason to promote cessation programs for smokeless tobacco as well.
The National Health and Nutrition Examination Survey III (NHANES III) study found that subgroups of men show highly different chewing tobacco use and quit rates, and the age at usage onset occurs across the lifespan. For these reasons, this group recommended that prevention and cessation programs should be specific to different risk groups and distinct from smoking programs. ${ }^{93}$

Cessation techniques include education with the American Cancer Society, National Cancer Institute, and Centers for Disease Control and Prevention literature, and chewing alternatives that can address the issues of oral gratification, the ritual associated with pulling out a can, opening it, and placing a pinch between gum and cheek, while at the same time addressing issues of peer pressure. Some have tried sunflower seeds, bubble gum, sugarless candy and nontobacco mint chews, that come in the same packaging and have the look, feel and behavior of tobacco chews. ${ }^{94}$ These chewing alternatives can be combined with NRTs. ${ }^{94,95}$ Mint and other herbal non-nicotine moist snuff does not enhance treatment outcomes when used with NRT patches, but it does reduce cravings and withdrawal symptoms. 96,97 Consistency is the most important factor. Ask every patient (especially adolescents) on each visit if they use tobacco. Find out if the patient is ready to quit. Unless ready (patient is in the contemplation or preparation phase) chances of quitting are very low. Physicians should offer help and be readily available. ${ }^{94}$

\section{Cultural and ethnic minorities}

The Surgeon General has issued a report on the ethnic and cultural differences that are to be considered among specific populations. It appears that differences in the magnitude of disease risk are directly related to differences in patterns of smoking. 98

Serum cotinine (a nicotine metabolite) levels have been found to be higher among black smokers than among white or Mexican American smokers. This may help explain why blacks find it harder to quit and are more likely to experience higher rates of lung cancer than white smokers. ${ }^{99}$ Lung cancer rates are lower in Asians and Latinos than Whites. ${ }^{100}$ Chinese Americans exhibit a lower nicotine intake per cigarette, smoke fewer cigarettes per day, and exhibit a slower clearance of nicotine. The implication is that Chinese Americans, and perhaps other Asians, may require lower doses of NRTs. ${ }^{100}$ Latinos exhibit similar nicotine intake per cigarette to whites, but smoke fewer cigarettes.

In Alaska, Native Americans use NRTs only if provided free of charge. If any price is charged, tobacco is used instead. ${ }^{94}$ Tobacco usage is also a part of the religious practice in many Native American cultures. The ceremonial tobacco ritual comes from the Native American practice of sending smoke to the Creator when asking for peace. Sensitivity to these uses must be respected. 
Adolescents

Adolescent tobacco use presents a special problem. 101 Sociodemographic, environmental and personal factors put youth at an increased risk of initiating tobacco use. Adolescents from families of low socioeconomic status are at increased risk of smoking. Environmental risk factors include cigarette advertising and promotion practices; the price, accessibility and availability of tobacco products; perceptions that tobacco use is normal among peers and siblings; and lack of parental involvement and influence in the adolescent's daily life. Personal risk factors include the belief that tobacco use provides a benefit, low self-image and low self-esteem, and the lack of ability to refuse offers to use tobacco. ${ }^{102}$

Eighty percent of tobacco users begin use before 18 years of age. ${ }^{4}$ Among adolescents the order of tobacco usage is cigarettes, cigars, smokeless tobacco products and pipe smoking. Cigarette usage among high school students increased during the $1990 \mathrm{~s}$, peaking in 1996 to 1997 at $70.2 \%$ lifetime users, and $36.4 \%$ current users. In 2000 there was a gradual decline to $64.0 \%$ lifetime users and $34.5 \%$ current users. ${ }^{4,103}$ It is the goal of Healthy People 2010 to reduce the total tobacco use by students in grades 9 through 12 from $40 \%$ (1999) to $21 \%$ (2010), increase the average age of first use of tobacco products by adolescents and young adults, reduce the initiation of tobacco use among children and adolescents, increase tobacco use cessation attempts by adolescent smokers to $84 \%$ from a baseline of $76 \%$ (1999), and increase disapproval of smoking by adolescent to $95 \%$ (2010). ${ }^{14}$

Among ninth graders, those exposed to peers who smoke and those with greater depressive symptoms were 2 to 3 times more likely to currently use an alternate tobacco product: $8.3 \%$ alternate product, $11 \%$ cigarettes $(45 \%$ of whom used both). ${ }^{104}$ More than half of middle and high school smokers report that they want to quit. ${ }^{4}$

Young males in the military are at an elevated risk of smokeless tobacco use relative to the general population. ${ }^{105}$ Especially in rural areas, snuff and chewing tobacco are becoming increasingly popular among male youths. Adolescents report a desire to have a circle on their back pocket ("ring on the rear") to fit in with other young chewing peers. 88,94 Other reasons for chewing are ritual and oral gratification, nicotine addiction (as many as 1 to 3 cans/week might be consumed), and salt cravings (1,100 mg/can). Salt cravings may be confused with nicotine withdrawal.

Flavored foreign cigarettes are becoming popular among teenagers in the United States. ${ }^{106,107}$ These include kretek (Indonesian cigarettes containing approximately 60\% tobacco and $40 \%$ ground clove buds), and bidis (hand-rolled cigarettes imported from India). ${ }^{107-109}$ Bidis are available in a variety of exotic (e.g., clove, mango) and candy-like (e.g., chocolate, raspberry) flavors. Adolescents perceive them as a safer, more natural alternative to conventional cigarette smoking, but bidis contain a higher concentration of nicotine than conventional filtered or unfiltered cigarettes. ${ }^{110}$
Certain tobacco flavorings contain alkenylbenzenes and other toxic or carcinogenic chemicals. The highest eugenol and trans-anethole concentrations found in bidi tobacco were about 70,000 and 7,500 times greater, respectively, than the highest levels previously found in United States cigarette brands. ${ }^{111}$ Youths found to be using kretek or bidi as a "more natural" alternative to cigarette smoking should be made aware of these facts.

\section{Women}

Women who smoke have twice the risk of myocardial infarction and lung cancer than men. The risk of myocardial infarction and stroke is further exacerbated in women on oral contraceptives. ${ }^{112,113}$ Other effects of tobacco use particular to women are an increased risk of breast cancer, increased menstrual bleeding and duration of dysmenorrhea, greater variability of menstrual cycle length, more difficulty in getting pregnant, and reaching menopause 1 to 2 years earlier. ${ }^{12,113}$ There is an unfounded tendency on the part of providers not to treat women with cardiovascular disease with NRTs. 114

More men than women quit with combined cognitive/behavioral group therapy and sustained release bupropion. ${ }^{115}$ Quitting smoking has been reported to be harder for women than men, partially because of concern of the perceived potential for weight gain if they quit. ${ }^{112,113}$ Other reasons that women may have a more difficult time in quitting include NRTs (especially gum and patches) may not be as effective in women, the medications to aid smoking cessation are not recommended for pregnant women, the menstrual cycle affects tobacco withdrawal symptoms and response to antismoking drugs vary by cycle phase, husbands provide less effective support to women than women give to men, women may be more susceptible to environmental cues (such as friends and moods) associated with the smoking ritual, and some women may enjoy the feeling of control associated with smoking. ${ }^{112,113}$ Antidepressant therapy may be more effective in women in that negative moods are more likely to precipitate smoking relapses in some women. A woman's success can hinge on the partner's smoking status, so it is advised to treat both partners at the same time. ${ }^{116}$ It is worthwhile noting that the same holds true for a male's success in smoking cessation.

A clinician's tendency to stereotype in certain situations may also come into play. Primary care residents have been found to stereotype when they assess the receptivity to smoking cessation advice on the part of lower middle-class, white female patients. ${ }^{117-119}$

Young women generally have low awareness of the health risks of smoking to the developing fetus of pregnant women and children of postpartum women. Nor are they aware of the effectiveness of NRT for doubling quit rates. ${ }^{120}$ Smoking during pregnancy increases the risk of low birth weight, miscarriage and sudden infant death syndrome. ${ }^{116}$ Some epidemiological studies have suggested that maternal smoking during pregnancy may increase the risk of childhood brain 
tumors, but meta-analysis has not borne this out. ${ }^{121}$ However, similar meta-analysis has suggested that paternal smoking during pregnancy is associated with pediatric brain tumor development, perhaps as a result of the mother breathing unfiltered versus filtered tobacco smoke. ${ }^{122}$

It has been reported that even when mothers inquire about their tobacco use, especially when children have environmental tobacco smoke-related conditions, pediatrician-provided smoking cessation counseling is very infrequent. ${ }^{123}$ Self-help approaches to smoking cessation in pregnancy are ineffective when implemented during routine antenatal care, so more complex interventions that are appropriately targeted and tailored to the pregnant woman are needed. ${ }^{116}$

New educational materials for women are being developed. In one report, a 14-minute interactive computer-mediated smoking cessation program was tested for low-income innercity women. Results suggested that $79 \%$ reported at least one behavioral change related to smoking. ${ }^{124}$

\section{Users of multiple forms of tobacco}

Concomitant users of cigarettes and smokeless tobacco products may need special treatment. Concomitant use is high in males, but nonexistent in females. While indicators of nicotine dependence may predict cessation success in either smokeless tobacco users or smokers, the predictions fail in concomitant users. The TTM also does not predict tobacco cessation success in concomitant users. ${ }^{125}$

\section{Medicaid recipients}

The 2000 Public Health Service Practice Guidelines conclude that advice and counseling has clinical and cost reduction benefits. They recommend health insurance coverage for services that help smokers kick the habit. ${ }^{5}$

One of the largest concerns for low-income smokers who want to quit is how to pay for smoking cessation medications and counseling programs, yet more than one-quarter of low-income citizens who smoke (i.e., 36\% [1.5 million persons]) cannot turn to Medicaid for help in quitting smoking. ${ }^{126}$ As of 2002, 16 states covered some form of counseling for pregnant smokers. Of these, 10 state Medicaid programs offer tobacco dependence treatment specifically for expectant mothers (all but one include some form of counseling). ${ }^{5}$ Medicaid covers bupropion in $32 \%$ of the states, but fewer than 10 states cover patches, inhalers, nasal sprays, or gums..$^{5}$ It has been proposed that states be required to cover effective treatment as part of federallymandated Medicaid benefits. ${ }^{5}$ Providing smoking cessation benefits alone is not likely to change the use of bupropion, patches or gum, or increase the rates of quitting unless accompanied by increased efforts to make smokers aware of insurance benefits and adding other types of cessation support. ${ }^{127-131}$

\section{CONCLUSION}

The deleterious effects of tobacco use are well known by both patients and clinicians. However, that knowledge does not presently translate effectively into patients quitting. A concerted, office-wide effort that includes office nursing and receptionist staff must be made to identify, educate and treat patients who use tobacco. Proven, brief, repetitive, directed interventions tailored to the needs of the patient and behavioral stage, can increase successful cessation attempts. Pharmacotherapy is available to help patients struggling with nicotine addiction and dependence, and to give them tools to move through the behavioral stages. All healthcare providers are obliged to use these proven techniques to advocate for the patient's better health. Ultimately, systemwide changes are needed to fully achieve the goals of Healthy People 2010. ${ }^{14}$ Benefits stand to be gained not only by the tobacco user, but also non-users, health insurers, healthcare organizations and society as a whole. The clinician must play a front line role because. If tobacco cessation is not made a priority with every patient, who else will intervene for smokers?

\section{ACKNOWLEDGMENTS}

The authors thank Marshfield Clinic Research Foundation for its support through the assistance of Alice Stargardt, Doreen Luepke and Dr. Graig Eldred in the preparation of this manuscript.

\section{REFERENCES}

1. Greden JF, Pomerleau O. Caffeine-related disorders and nicotinerelated disorders. In: Kaplan HI, Sadock BJ, Cancro R, editors. Comprehensive Textbook of Psychiatry. 6th ed. Baltimore: Williams \& Wilkins; 1995. p. 806-811.

2. Centers for Disease Control and Prevention. Tobacco Information and Prevention Source (TIPS). Surgeon General's Reports. Available at: http:/www.cdc.gov/ tobacco/sgrpage.htm. Accessed June 5, 2003.

3. Smoking-attributable mortality and years of potential life lost-United States, 1984. MMWR Morb Mortal Wkly Rep 1997;46:444-451.

4. Youth tobacco surveillance-United States, 2000. MMWR CDC Surveill Summ 2001;50:1-84.

5. ASCO. American Society of Clinical Oncology Policy Statement Update: Tobacco Control-Reducing Cancer Incidence and Saving Lives. JClinOncol 2003;21:1-10.

6. Doll R, Peto R, Wheatley K, Gray R, Sutherland I. Mortality in relation to smoking: 40 years' observations on male British doctors. BMJ 1994;309:901-911.

7. Miller LS, Zhang X, Novotny T, Rice DP, Max W. State estimates of Medicaid expenditures attributable to cigarette smoking, fiscal year 1993. Public Health Rep 1998;113:140151.

8. Zhang X, Miller L, Max W, Rice DP. Cost of smoking to the Medicare program, 1993. Health Care Financ Rev 1999;20:179-196.

9. Giovino GA, Schooley MW, Zhu BP, Chrismon JH, Tomar SL, Peddicord JP, Merritt RK, Husten CG, Eriksen MP. Surveillance for selected tobacco-use behaviors-United States, 1900-1994. MMWR CDC Surveill Summ 1994;43:143.

10. Cigarette smoking among adults-United States, 1997. MMWR Morb Mortal Wkly Rep 1999;48:993-996. 
11. Cigarette smoking among adults-United States, 2000. MMWR Morb Mortal Wkly Rep 2002;51:642-645.

12. California Department of Health Services. Tobacco Control Section. California tobacco control update. Sacramento: California Department of Health Services; 2000.

13. Bitton A, Fichtenberg C, Glantz S. msJAMA: reducing smoking prevalence to $10 \%$ in five years. JAMA 2001;286:27332734.

14. U.S. Department of Health and Human Services. Tobacco use. In: Healthy people 2010. 2nd ed. With understanding and improving health and objectives for improving health, 2 vols. Washington, DC: U.S. Government Printing Office; November 2000. 27.1-27.40.

15. Hopkins DP, Briss PA, Ricard CJ, Husten CG, Carande-Kulis VG, Fielding JE, Alao MO, McKenna JW, Sharp DJ, Harris JR, Woollery TA, Harris KW; Task Force on Community Preventive Services. Reviews of evidence regarding interventions to reduce tobacco use and exposure to environmental tobacco smoke. Am J Prev Med 2001;20(2 uppl):16-66.

16. Centers for Disease Control and Prevention. The health consequences of smoking: nicotine addiction-a report by the Surgeon General. Rockville, MD: US Department of Health and Human Services, Public Health Service. 1988; DHHS publication no. (CDC)88-8406.

17. United States Department of Health and Human Services. The health benefits of smoking cessation. Rockville, MD: U.S. DHHS, Public Health Service, Centers for Disease Control and Prevention. 1990; DHHS publication no. (CDC) 908416.

18. Chao A, Thun MJ, Henley SJ, Jacobs EJ, McCullough ML, Calle EE. Cigarette smoking, use of other tobacco products and stomach cancer mortality in US adults: The Cancer Prevention Study II. Int J Cancer 2002;101:380-389.

19. Dickerson TJ, Janda KD. A previously undescribed chemical link between smoking and metabolic disease. Proc Natl Acad Sci USA 2002;99:15084-15088.

20. National Cancer Institute. Health effects of exposure to environmental tobacco smoke: the report of the California Environmental Protection Agency. Smoking and Tobacco Control Monograph No 10. Bethesda, MD: U.S. Department of Health and Human Services, National Institutes of Health, National Cancer Institute; 1999. NIH publication no 99-4645.

21. He J, Vupputuri S, Allen K, Prerost MR, Hughes J, Whelton PK. Passive smoking and the risk of coronary heart disease-a meta-analysis of epidemiologic studies. N Engl J Med 1999;340:920-926.

22. Thun M, Henley J, Apicella L. Epidemiologic studies of fatal and nonfatal cardiovascular disease and ETS exposure from spousal smoking. Environ Health Perspect 1999;107(suppl 6):841-846.

23. Huncharek M, Kupelnick B, Klassen H. Paternal smoking during pregnancy and the risk of childhood brain tumors: results of a meta-analysis. In Vivo 2001;15:535-541.

24. Enstrom JE, Kabat GC. Environmental tobacco smoke and tobacco related mortality in a prospective study of Californians, 1960-98. BMJ 2003;326:1057.

25 . Tonnesen P. Smoking reduction for smokers not able or motivated to quit? Respiration 2002;69:475-478.

26. Godtfredsen NS, Holst C, Prescott E, Vestbo J, Osler M. Smoking reduction, smoking cessation, and mortality: a 16year follow-up of 19,732 men and women from The Copenhagen Centre for Prospective Population Studies. Am J Epidemiol 2002;156:994-1001.

27. Shields PG. Tobacco smoking, harm reduction, and biomarkers. J Natl Cancer Inst 2002;94:1435-1444.

28. Lightwood JM, Glantz SA. Short-term economic and health benefits of smoking cessation: myocardial infarction and stroke. Circulation 1997;96:1089-1096.
29. Lightwood JM, Phibbs CS, Glantz SA. Short-term health and economic benefits of smoking cessation: low-birth weight. Pediatrics 1999; 104:1312-1320.

30. Hymowitz N, Cummings KM, Hyland A, Lynn WR, Pechacek TF, Hartwell TD. Predictors of smoking cessation in a cohort of adult smokers followed for five years. Tob Control 1997;6(suppl 2):S57-S62.

31. Spangler JG, George G, Foley KL, Crandall SJ. Tobacco intervention training: current efforts and gaps in US medical schools. JAMA 2002;288:1102-1109.

32. Stone TT, Longo DR, Phillips RL Jr, Hewett JE, Riley SL. Health care system and insurer support for smoking cessation guideline implementation. J Health Care Finance 2002;29:7886.

33. Eddy DM. David Eddy ranks the tests. Harv Health Lett 1992;17(suppl):10-11.

34. The Agency for Health Care Policy and Research Smoking Cessation Clinical Practice Guideline. JAMA 1996;275:1270-1280.

35. Fiore MC, Bailey WC, Cohen SJ, Dorfman SF, Goldstein MG, Gritz ER, Heyman RB, Jaén CR, Kottke TE, Lando HA, Mecklenburg RE, Mullen PD, Nett LM, Robinson L, Stitzer ML, Tommasello AC, Villejo L, Wewers ME. Treating tobacco use and dependence, June 2000. U.S. Department of Health and Humans Services, Public Health Service. Available at: http://www.surgeongeneral.gov/tobacco/treating_tobacco_use.pdf. Accessed June 6, 2003.

36. Tobacco Use and Dependence Clinical Practice Guideline Panel, Staff, and Consortium Representatives. A clinical practice guideline for treating tobacco use and dependence: A US Public Health Service report. JAMA 2000;283:32443254.

37. Mallin R. Smoking cessation: integration of behavioral and drug therapies. Am Fam Physician 2002;65:1107-1114.

38. Law M, Tang JL. An analysis of the effectiveness of interventions intended to help people stop smoking. Arch Intern Med 1995; 155:1933-1941.

39. Murray RP, Connett JE, Rand CS, Pan W, Anthonisen NR. Persistence of the effect of the Lung Health Study (LHS) smoking intervention over eleven years. Prev Med 2002;35:314-319.

40. Treating tobacco use and dependence-a systems approach. A guide for health care administrators, insurers, managed care organizations, and purchasers, November 2000. U.S. Public Health Service. Available at http://www.surgeongeneral.gov/ tobacco/systems.htm. Accessed June 6, 2003.

41. Glynn TJ, Manley MW. How to help your patients stop smoking: a National Cancer Institute manual for physicians. Bethesda, MD: National Cancer Institute. 1993; NIH publication no 93-3064.

42. Tønnesen P, Paoletti P, Gustavsson G, Russell MA, Saracci R, Gulsvik A, Rijcken B, Sawe U; Collaborative European AntiSmoking Evaluation. European Respiratory Society. Higher dosage nicotine patches increase one-year smoking cessation rates: results from the European CEASE trial. Eur Respir J 1999; 13:238-246.

43. Prochaska JO, DiClemente CC. Stages and processes of selfchange of smoking: toward an integrative model of change. J Consult Clin Psychol 1983;51:390-395.

44. Canadian Council on Smoking and Health; Ottawa: Canadian Council on Smoking and Health, College of Family Physicians of Canada. Guide your patients to a smoke free future. 1992-06; monograph CNGO 92.26.

45. Eberman KM, Patten CA, Dale LC. Counseling patients to quit smoking. What to say, when to say it, and how to use your time to advantage. Postgrad Med 1998;104:89-94.

46. Kaye L. Pharmacologic and behavioral approaches to smoking cessation. Hosp Medicine 1998;34:41-50. 
47. Smith SS, Jorenby DE, Leischow SJ, Nides MA, Rennard SI, Johnston JA, Jamerson B, Fiore MC, Baker TB. Targeting smokers at increased risk for relapse: treating women and those with a history of depression. Nicotine Tob Res 2003;5:99-109.

48. Krall EA, Garvey AJ, Garcia RI. Smoking relapse after 2 years of abstinence: findings from the VA Normative Aging Study. Nicotine Tob Res 2002;4:95-100.

49. Glavas D, Rumboldt M, Rumboldt Z. Smoking cessation with nicotine replacement therapy among health care workers: randomized double-blind study. Croat Med J 2003;44:219224.

50. Prochaska JO, Goldstein MG. Process of smoking cessation. Implications for clinicians. Clin Chest Med 1991;12:727-735.

51. Fiore MC, Bailey WC, Cohen SJ, Dorfman SF, Goldstein MG, Gritz ER, Heyman RB, Jaén CR, Kottke TE, Lando HA, Mecklenburg RE, Mullen PD, Nett LM, Robinson L, Stitzer ML, Tommasello AC, Villejo L, Wewers ME. Treating tobacco use and dependence. Quick reference guide for clinicians, October 2000. U.S. Department of Health and Humans Services, Public Health Service. Available at http://www.surgeongeneral.gov/tobacco/tobaqrg.htm. Accessed June 6, 2003.

52. Manley MW, Epps RP, Glynn TJ. The clinician's role in promoting smoking cessation among clinic patients. Med Clin North Am 1992;76:477-494.

53. King CM, Rothman AJ, Jeffery RW. The Challenge study: theory-based interventions for smoking and weight loss. Health Educ Res 2002;17:522-530.

54. Williams GC, Minicucci DS, Kouides RW, Levesque CS, Chirkov VI, Ryan RM, Deci EL. Self-determination, smoking, diet and health. Health Educ Res 2002;17:512-521.

55. Mansvelder HD, McGehee DS. Long-term potentiation of excitatory inputs to brain reward areas by nicotine. Neuron 2000;27:349-357.

56. Mansvelder HD, Keath JR, McGehee DS. Synaptic mechanisms underlie nicotine-induced excitability of brain reward areas. Neuron 2002;33:905-919.

57. National Institute on Drug Abuse. Research report series nicotine addiction. Available at: http://www.nida.nih.gov/ researchreports/nicotine/nicotine3.html. Accessed June 6, 2003.

58. Benowitz NL. Cigarette smoking and nicotine addiction. Med Clin North Am 1992;76:415-437.

59. Hughes JR, Goldstein MG, Hurt RD, Shiffman S. Recent advances in the pharmacotherapy of smoking. JAMA 1999;281:72-76.

60. MacKenzie TD. New strategies for smoking cessation. Hosp Pract 1999;34:25-26, 29.

61. Dale LC, Hurt RD, Hays JT. Drug therapy to aid in smoking cessation. Tips on maximizing patients' chances for success. Postgrad Med 1998;104:75-78, 83-84.

62. Sutherland G. Current approaches to the management of smoking cessation. Drugs 2002;62(suppl 2):53-61.

63. Fant RV, Henningfield JE, Shiffman S, Strahs KR, Reitberg DP. A pharmacokinetic crossover study to compare the absorption characteristics of three transdermal nicotine patches. Pharmacol Biochem Behav 2000;67:479-482.

64. Shiffman S, Elash CA, Paton SM, Gwaltney CJ, Paty JA, Clark DB, Liu KS, Di Marino ME. Comparative efficacy of 24hour and 16-hour transdermal nicotine patches for relief of morning craving. Addiction 2000;95:1185-1195.

65. Kotlyar M, Golding M, Hatsukami DK, Jamerson BD. Effect of nonnicotine pharmacotherapy on smoking behavior. Pharmacotherapy 2001;21:1530-1548.

66. Hughes JR, Stead LF, Lancaster T. Anxiolytics for smoking cessation (Cochrane review). In: The Cochrane Library, issue 2. Oxford: Update Software; 2003.
67. Dong J, Blier P. Modification of norepinephrine and serotonin, but not dopamine, neuron firing by sustained bupropion treatment. Psychopharmacology (Berl) 2001;155:52-57.

68. Jorenby DE, Leischow SJ, Nides MA, Rennard SI, Johnston JA, Hughes AR, Smith SS, Muramoto ML, Daughton DM, Doan K, Fiore MC, Baker TB. A controlled trial of sustainedrelease bupropion, a nicotine patch, or both for smoking cessation. N Engl J Med 1999;340:685-691.

69. Ferry L, Johnston JA. Efficacy and safety of bupropion SR for smoking cessation: data from clinical trials and five years of postmarketing experience. Int J Clin Pract 2003;57:224-230.

70. Piasecki TM, Fiore MC. Consultations \& comments. Putting smokers in the mood to quit. Consultant 1998;38:240.

71. Gourlay SG, Stead LF, Benowitz NL. Clonidine for smoking cessation. Cochrane Database Syst Rev 2000;(2):CD000058.

72. Hall SM, Humfleet GL, Reus VI, Munoz RF, Hartz DT, Maude-Griffin R. Psychological intervention and antidepressant treatment in smoking cessation. Arch Gen Psychiatry 2002;59:930-936.

73. Kotlyar M, Hatsukami DK. Managing nicotine addiction. J Dent Educ 2002;66:1061-1073.

74. Center for Disease Control and Prevention, Tobacco Information and Prevention Source (TIPS). Reducing tobacco use. A report of the Surgeon General (2000). Available at: http://www.cdc.gov/tobacco/sgr_tobacco_use.htm. Accessed June 6, 2003.

75. U.S. Food and Drug Administration. FDA warns sellers of nicotine lollipops \& lip balm that their products are illegal. FDA Talk Paper (T02-17), April 10, 2002. Available at: http://www.fda.gov/bbs/topics/ANSWERS/2002/ANS01144. html. Accessed June 6, 2003.

76. 'Nicotine water' is unapproved drug. FDA Consum 2002;36:5.

77. White AR, Rampes H, Ernst E. Acupuncture for smoking cessation. Cochrane Database Syst Rev. 2002;(2):CD000009.

78. Abbot NC, Stead LF, White AR, Barnes J, Ernst E. Hypnotherapy for smoking cessation. Cochrane Database Syst Rev 2000;(2):CD001008.

79. Middleton ET, Morice AH. Breath carbon monoxide as an indication of smoking habit. Chest 2000;117:758-763.

80. Jacob P 3rd, Hatsukami D, Severson H, Hall S, Yu L, Benowitz NL. Anabasine and anatabine as biomarkers for tobacco use during nicotine replacement therapy. Cancer Epidemiol Biomarkers Prev 2002;11:1668-1673.

81. Gerasimov MR, Schiffer WK, Gardner EL, Marsteller DA, Lennon IC, Taylor SJ, Brodie JD, Ashby CR Jr, Dewey SL. GABAergic blockade of cocaine-associated cue-induced increases in nucleus accumbens dopamine. Eur J Pharmacol 2001;414:205-209.

82. Paul M, Dewey SL, Gardner EL, Brodie JD, Ashby CR Jr. Gamma-vinyl GABA (GVG) blocks expression of the conditioned place preference response to heroin in rats. Synapse 2001;41:219-220.

83. Gardner EL, Schiffer WK, Horan BA, Highfield D, Dewey SL, Brodie JD, Ashby CR Jr. Gamma-vinyl GABA, an irreversible inhibitor of GABA transaminase, alters the acquisition and expression of cocaine-induced sensitization in male rats. Synapse 2002;46:240-250.

84. Lerman C, Shields PG, Wileyto EP, Audrain J, Pinto A, Hawk L, Krishnan S, Niaura R, Epstein L. Pharmacogenetic investigation of smoking cessation treatment. Pharmacogenetics 2002;12:627-634.

85. Marcy TW, Stefanek M, Thompson KM. Genetic testing for lung cancer risk. J Gen Intern Med 2002;17:946-951.

86. Rodu B, Cole P. Smokeless tobacco use and cancer of the upper respiratory tract. Oral Surg Oral Med Oral Pathol Oral Radiol Endod 2002;93:511-515. 
87. Tilashalski K, Rodu B, Cole P. A pilot study of smokeless tobacco in smoking cessation. Am J Med 1998;104:456-458.

88. Prokhorov AV, Wetter DW, Padgett D, de MC, Le T, Kitzman H. Spit tobacco prevention and cessation counseling: statewide survey of health-care professionals and educators. Subst Use Misuse 2002;37:171-197.

89. Rodu B, Cole P. Smokeless tobacco use and cancer of the upper respiratory tract. Oral Surg Oral Med Oral Pathol Oral Radiol Endod 2002;93:511-515.

90. U.S. Department Health and Human Services. The health consequences of using smokeless tobacco use. A report of the Advisory Committee to the Surgeon General. Washington, DC; 1986. DHHS publication no (NIH)86-2874.

91. Using smokeless tobacco is gambling with your health! Available at: http://www.quittobacco.com/facts/effects.htm. Accessed June 6, 2003.

92. Mansvelder HD, McGehee DS. Cellular and synaptic mechanisms of nicotine addiction. J Neurobiol 2002;53:606-617.

93. Howard-Pitney B, Winkleby MA; National Health and Nutrition Examination Survey III. Chewing tobacco: who uses and who quits? Findings from NHANES III, 1988-1994. Am J Public Health 2002;92:250-256.

94. Healthy substitute for cigarettes and chewing tobacco. Available at: http://www.quittobacco.com/cessfldr/cessation.htm. Accessed June 6, 2003.

95. Glover ED, Glover PN, Sullivan CR, Cerullo CL, Hobbs G. A comparison of sustained-release bupropion and placebo for smokeless tobacco cessation. Am J Health Behav 2002;26:386-393.

96. Hatsukami DK, Grillo M, Boyle R, Allen S, Jensen J, Bliss R, Brown S. Treatment of spit tobacco users with transdermal nicotine system and mint snuff. J Consult Clin Psychol 2000;68:241-249.

97. McChargue DE, Collins FL Jr, Cohen LM. Effect of non-nicotinic moist snuff replacement and lobeline on withdrawal symptoms during 48-h smokeless tobacco deprivation. Nicotine Tob Res 2002;4:195-200.

98. Center for Disease Control and Prevention. Tobacco Information and Prevention Source (TIPS). Tobacco use among U.S. racial/ethnic minority groups. A report of the Surgeon General (1998). Available at: http://www.cdc.gov/ tobacco/sgr-minorities.htm. Accessed March 14, 2003.

99. Caraballo RS, Giovino GA, Pechacek TF, Mowery PD, Richter PA, Strauss WJ, Sharp DJ, Eriksen MP, Pirkle JL, Maurer KR. Racial and ethnic differences in serum cotinine levels of cigarette smokers: Third National Health and Nutrition Examination Survey, 1988-1991. JAMA 1998;280:135-139.

100. Benowitz NL, Perez-Stable EJ, Herrera B, Jacob P 3rd. Slower metabolism and reduced intake of nicotine from cigarette smoking in Chinese-Americans. J Natl Cancer Inst 2002;94:108-115.

101. Center for Disease Control and Prevention, Tobacco Information and Prevention Source. Preventing tobacco use among young people. A report of the Surgeon General (1994). Available at: http://www.cdc.gov/tobacco/ sgryth2.htm. Accessed March 14, 2003.

102. U.S. Department of Health and Human Services. Preventing tobacco use among young people: a report of the Surgeon General. Atlanta, GA: Department of Health and Human Services, Public Health Service, Centers for Disease Control and Prevention, National Center for Chronic Disease Prevention and Health Promotion, Office on Smoking and Health, 1994.

103. Tobacco use among high school students-United States, 1997. MMWR Morb Mortal Wkly Rep 1998;47:229-233.
104. Tercyak KP, Audrain J. Psychosocial correlates of alternate tobacco product use during early adolescence. Prev Med 2002;35:193-198.

105. Cigrang JA, Severson HH, Peterson AL. Pilot evaluation of a population-based health intervention for reducing use of smokeless tobacco. Nicotine Tob Res 2002;4:127-131.

106. Taylor TM, Biener L. Bidi smoking among Massachusetts teenagers. Prev Med 2001;32:89-92.

107. Malson JL, Pickworth WB. Bidis-hand-rolled, Indian cigarettes: effects on physiological, biochemical and subjective measures. Pharmacol Biochem Behav 2002;72:443-447.

108. Clark GC. Comparison of the inhalation toxicity of kretek (clove cigarette) smoke with that of American cigarette smoke. I. One day exposure. Arch Toxicol 1989;63:1-6

109. Clark GC. Comparison of the inhalation toxicity of kretek (clove cigarette) smoke with that of American cigarette smoke. II. Fourteen days, exposure. Arch Toxicol 1990;64:515-521.

110. Malson JL, Sims K, Murty R, Pickworth WB. Comparison of the nicotine content of tobacco used in bidis and conventional cigarettes. Tob Control 2001;10:181-183.

111. Stanfill SB, Calafat AM, Brown CR, Polzin GM, Chiang JM, Watson $\mathrm{CH}$, Ashley DL. Concentrations of nine alkenylbenzenes, coumarin, piperonal and pulegone in Indian bidi cigarette tobacco. Food Chem Toxicol 2003;41:303-317.

112. Centers for Disease Control and Prevention, Tobacco Information and Prevention Source (TIPS). Women and smoking. A report of the Surgeon General-2001. Available at: http://www.cdc.gov/tobacco/sgr_forwomen.htm. Accessed March 14, 2003.

113. Perkins KA. Smoking cessation in women. Special considerations. CNS Drugs 2001;15:391-411.

114. Mahrer-Imhof R, Froelicher ES, Li WW, Parker KM, Benowitz N. Women's Initiative for Nonsmoking (WINS V): under-use of nicotine replacement therapy. Heart Lung 2002;31:368-373.

115. Earles J, Folen RA, Ma M, Kellar M, Geralde R, Dydek C. Clinical effectiveness of sustained-release bupropion and behavior therapy for tobacco dependence in a clinical setting. Mil Med 2002;167:923-925.

116. Moore L, Campbell R, Whelan A, Mills N, Lupton P, Misselbrook E, Frohlich J. Self help smoking cessation in pregnancy: cluster randomized controlled trial. BMJ 2002;325:1383.

117. Pollak KI, Taiwo B, Lyna P, Baldwin M, Lipkus IM, Bepler G, McBride CM. Reported cessation advice given to African Americans by health care providers in a community health clinic. J Community Health 2002;27:381-393.

118. Pollak KI, Arredondo EM, Yarnall KS, Lipkus I, Myers E, McNeilly M, Costanzo P. Influence of stereotyping in smoking cessation counseling by primary care residents. Ethn Dis 2002; 12:578-585.

119. Pollak KI, McBride CM, Scholes D, Grothaus LC, Civic D, Curry SJ. Women's reports of smoking cessation advice during reproductive health visits and subsequent smoking cessation. Am J Manag Care 2002;8:837-844.

120. Bonollo DP, Zapka JG, Stoddard AM, Ma Y, Pbert L, Ockene JK. Treating nicotine dependence during pregnancy and postpartum: understanding clinician knowledge and performance. Patient Educ Couns 2002;48:265-274

121. Huncharek M, Kupelnick B, Klassen H. Maternal smoking during pregnancy and the risk of childhood brain tumors: a meta-analysis of 6566 subjects from twelve epidemiological studies. J Neurooncol 2002;57:51-57. 
122. Huncharek M, Kupelnick B, Klassen H. Paternal smoking during pregnancy and the risk of childhood brain tumors: results of a meta-analysis. In Vivo 2001;15:535-541.

123. Sharif I, Oruwariye T, Waldman G, Ozuah PO. Smoking cessation counseling by pediatricians in an inner-city setting. $\mathrm{J}$ Natl Med Assoc 2002;94:841-845.

124. McDaniel AM, Hutchison S, Casper GR, Ford RT, Stratton R, Rembusch M. Usability testing and outcomes of an interactive computer program to promote smoking cessation in low income women. Proc AMIA Symp 2002;509-513.

125. Wetter DW, McClure JB, de Moor C, Cofta-Gunn L, Cummings S, Cinciripini PM, Gritz ER. Concomitant use of cigarettes and smokeless tobacco: prevalence, correlates, and predictors of tobacco cessation. Prev Med 2002;34:638-648.

126. State medicaid coverage for tobacco-dependence treatments-United States, 1998 and 2000. MMWR Morb Mortal Wkly Rep 2001;50:979-982.

127. Boyle RG, Solberg LI, Magnan S, Davidson G, Alesci NL. Does insurance coverage for drug therapy affect smoking cessation? Health Aff (Millwood) 2002;21:162-168.

128. Curry SJ, Grothaus LC, McAfee T, Pabiniak C. Use and cost effectiveness of smoking-cessation services under four insurance plans in a health maintenance organization. N Engl J Med 1998;339:673-679.

129. Schauffler HH. Defining benefits and payment for smoking cessation treatments. Tob Control 1997;6(suppl 1):S81-S85.

130. Schauffler HH, McMenamin S, Olson K, Boyce-Smith G, Rideout JA, Kamil J. Variations in treatment benefits influence smoking cessation: results of a randomised controlled trial. Tob Control 2001;10:175-180.

131. McPhillips-Tangum C. Results from the first annual survey on addressing tobacco in managed care. Tob Control 1998;7(suppl):S11-S13. 